\section{Birlesik Dünya Arastruma Global Journal of Psychology BD-CENTER \\ Innovasyon ve Yayınıılık Merkezi \\ Research: New Trends and \\ Issues}

Global Journal of Psychology Research: New Trends and Issues

Volume 10, Issue 1, (2020) 01-10

www.gjpr.eu

\title{
Father absence and sexual partner preference amongst women in Masvingo urban, Zimbabwe
}

\author{
Herbert Zirima*, Department of Psychology, Julius Nyerere School of Social Sciences, Great Zimbabwe \\ University, Masvingo P. Bag 1235, Zimbabwe https://orcid.org/0000-0002-4645-3879
}

\section{Suggested Citation:}

Zirima, H. (2020). Father absence and sexual partner preference amongst women in Masvingo urban, Zimbabwe. Global Journal of Psychology Research: New Trends and Issues. 10(1), 01-10. DOI: 10.18844/gjpr.v\%vi\%i.4116

Received October 20, 2019; revised February 10, 2020; accepted March 05, 2020.

Selection and peer review under responsibility of Prof. Dr. Tulay Bozkurt, Istanbul Kultur University, Turkey.

${ }^{\circ} 2020$ Birlesik Dunya Yenilik Arastirma ve Yayincilik Merkezi. All rights reserved.

\begin{abstract}
Father absence is a trend that has been on the surge globally and locally, and its effects can be felt in children's lives up to adulthood. This study sought to explore how father absence mediates sexual partner preference amongst women who would have grown without their biological fathers. This was achieved by comparing the sexual partner preferences of women who grew up without fathers against those who grew up with their fathers. A quantitative approach was taken, particularly employing an ex post facto research design. A one-stage cluster sampling strategy was used to select 392 women, who participated in this study. Of the 392 participants, 168 were women who had grown up in father-absent homes, whereas the remaining 224 had grown up with a resident father. A standardised instrument, the mate preference questionnaire, was used to collect data. This study revealed that father absence influences the preference of a sexual partner, particularly the age gap with the preferred romantic partner, physical aspects of the sexual partner and values about chastity. Women who grew up in fatherless homes showed a preference for good looks and masculinity in a romantic over issues such as good financial prospect and ambitiousness and industriousness. The most preferred characteristic expressed by women who emerged from father-absent homes was that the romantic partner should be a father figure. This study recommends that voluntary organisations that promote fatherhood programs should be set up to raise awareness on the importance of fathering. Moreover, future research should explore the impact of father absence amongst married women so as to ascertain if father absence affects relationships within a marriage.
\end{abstract}

Keywords: Partner preference, father absence, romantic partner, women, relationship.

* ADDRESS FOR CORRESPONDENCE: Zirima Herbert, Department of Psychology, Julius Nyerere School of Social Sciences, Great Zimbabwe University, Masvingo P. Bag 1235, Zimbabwe. E-mail address: hzirima@gzu.ac.zw / Tel.: +263775371313 


\section{Introduction}

Father absence is a steadily rising phenomenon globally and even locally. In the past two decades and beyond, a number of marriages have been ending in divorce parents; especially, fathers have been migrating to the diaspora in search of greener pastures (Centre for Disease Control and Prevention (CDC), 2015). Girls, in countries such as Zimbabwe and South Africa, are usually impregnated and left 'dumped' to take care of the child on their own, giving a trend known as 'single motherhood' (Baglama, 2017; Zirima \& Gadzikwa, 2017). The net effect of all these trends is a disappearance of fathers in the life of their children. This disappearance has far-reaching psychosocial implications in the life of children as they grow into adulthood. Boothroyd and Perrett (2008) defined father absence as referring to a situation, where a child has lived for part or all of their childhood in a house without their biological father.

The absence of a father figure in childhood can have ripple effects for a female child as they reach adulthood. Women who grew up without their fathers are prone to live in poor economic conditions and divorce and are highly likely to indulge in premarital sex and irresponsible sexual behaviour (Thomassin \& Suveg, 2014). These factors have an impact on the preference for a sexual partner that these women will have.

Boothroyd and Perrett (2008) postulated that father absence and/or early psychosocial stress are associated with the development of a more short-term relationship strategy in females. The shortterm relationship strategy is closely linked with low investment in relationships. They further predicted that women who grew up in father-absent homes or those who grew up in families with poor family relationships grow up to prefer more masculine men than women who grew up with their father or those who had warm family relationships. The sexual strategies perspective envisage that father absence causes the embracing of a short-term strategy to relationships and such an increased interest to male facial masculinity (Boothroyd \& Perrett, 2008).Early father absence was linked to considerably stronger masculinity preference in women likely to be ovulating and non-significantly weaker masculinity preference in women likely to be in the luteal stage of their cycle.

According to Horne (2015), adolescents with an absent father preferred to exert less commitment to their romantic partner and desired to take part in unsafe activities such as unprotected sex and sometimes pregnancy in their ideal relationship. This was common even when all other factors such as mother's socio-economic status, the child's age and race were controlled. Mancini (2010) revealed that girls from father-absent homes exhibited a desperate need for males to cover up for the emotional vulnerability caused by father absence. This condition may make them to prefer adult men in romantic relationships.

In South Africa, 36\% of children are brought up in father-absent homes (Meintjies \& Hall, 2010). Clearly, the indication is that such children will develop differently from those who are raised by their fathers. However, Makofane (2015) argued that the place of a father in the family should not be understood in relation to his physical absence or presence bearing in mind that father presence does not translate to father involvement. In a study in Cape Town, South Africa, Madhavan, Townsend and Garey (2012) posit that the physical or emotional absence of a father in a child's life can seriously affect a child later in life as they tend to be susceptible to a number of societal ills such as substance abuse, promiscuity, early and unwanted pregnancies crime and violence. These ills may moderate the sexual partner preferences of the children as they grow into adulthood.

This research was inspired by the need to break the jinx and find the truth about the impact of father absence on the girl child in Zimbabwe, particularly focusing on sexual partner preferences of women who grew up without fathers. This is so because there are divergent views on the effects of father absence on children. The western literature generally points to negative psychosocial effects for the girl child, whereas literature from Africa presents opposing views. Some African scholars have downplayed the importance of a father figure in nurturing the girl child (Makofane, 2015; Meintjies \& Hall, 2010; Mokomane, 2012; Ratele, Shefer \& Clowes, 2012). Makofane argued that the presence of a 
father is not significant because most of the fathers are not emotionally involved with their daughters. However, other research works in Africa point to psychosocial problems for children left behind by absent fathers (Hosegood \& Madhavan, 2010; Nyanjaya \& Masango, 2012). The argument posited by these scholars is that there can be no replacement for the presence of a biological father in a child's life and that the absence of father leads to poor psychosocial adjustment in the development of a child. These contradictory findings clearly show the need to ascertain the nature of father absence (whether it is due to divorce, emigration or incarceration) and the socioeconomic status of the absent father and the resident mother as these have variable effects on the adult life of the girl who grows up with an absent father.

\subsection{Aim}

This study sought to ascertain the influence of father absence on sexual partner preference by comparing sexual partner preferences of women from father-absent homes against those of women who grew up with a resident father.

\subsection{Objectives}

The specific objectives of this study are to:

1. Ascertain if preferred psychosocial characteristics in a romantic partner differ between women who grew up in father-absent households from those of women who grew up with their fathers;

2. Assess if preferred physical characteristics in a romantic partner differ between women who grew up in father-absent households from those of women who grew up with their fathers;

\subsection{Hypothesis}

Ho: Sexual partner preference of women who grew up with their fathers does not significantly differ from that of women who grew up without their fathers.

\section{Methodology}

This research took a quantitative approach specifically using the expost facto design. Cohen, Manion and Morrison (2000) defined ex post facto research design as that in which the independent variable has already occurred and the researcher starts with the observation of a dependent variable. The design was chosen because it best suits the variables that this research seeks to investigate. The independent variable in this research has already occurred (father absence), and the researcher sought to find its relationship or its influence to a number of dependent variables, most of which have already occurred.

The population for this study consisted of all women in Mucheke suburb aged between the 18 and 39. A total of 392 participants between the ages of 18 and 39 took part in this study. About $43 \%$ of women who participated in this study grew up in father-absent homes, whereas $57 \%$ grew up with a resident father.

The participants were selected using one-stage cluster sampling. Cluster sampling involves the selection of groups of study units (clusters) instead of the selection of study units individually (Aye et al. 2016; Mikaeli Manee \& Aria, 2018; Punch, 2004). 
This research made use of the mate preference questionnaire to collect the data. The instrument explores factors that were considered by people in choosing a sexual and marriage partner. The questionnaire required participants to rate 18 characteristics on how important or desirable each would be in choosing a mate, and a four-point scale was used. The scale also lists a set of characteristics that are preferred in a potential mate or marriage partner. Respondents were then asked to rank those characteristics from most to least preferred.

The Statistical Package for the Social Sciences version 21.0 was used to analyse the data. The Chisquare test for independence was specifically used to test for significance in differences.

\section{Results and discussion}

This study sought to ascertain the impact of father absence on sexual partner preference of women from father-absent homes. To ascertain the impact, a comparison between women who grew up with fathers and those who did not grow up with fathers with respect to preferred romantic partners and relationship strategies was done.

The study, therefore, sought to test the following hypothesis:

Ho: Sexual partner preference of women who grew up with their fathers does not significantly differ from that of women who grew up without their fathers

The hypothesis was tested using the Chi-square test of independence, and the results are shown in Table 1.

Table 1. Summary of chi-square values for differences in sexual partner preferences between women from father present homes and women from father-absent homes

\begin{tabular}{llll}
\hline Variable & Value & $\boldsymbol{D f}$ & $\boldsymbol{p}$ \\
\hline Age at marriage & 28.081 & 7 & $<0.01$ \\
Good looks of preferred partner & 8.893 & 3 & 0.031 \\
Masculinity & 13.150 & 3 & 0.04 \\
Most desired characteristic in a potential mate & 94.221 & 12 & $<0.01$ \\
\hline
\end{tabular}

The results in Table 1show that there were significant differences in the sexual partner preferences of women from father-absent homes as compared to those of women who grew up with their fathers. Therefore, the null hypothesis was rejected, and it was concluded that sexual partner preference of women who grew up with their fathers significantly differs from that of women who grew up without their fathers.

\subsection{Preferred marriage age and age difference with potential sexual partner}

This study revealed that father absence or presence during the first 18 years of life influences the age of marriage and the age difference with a potential sexual partner. There was a significant difference in the actual age of marriage between women from father-absent homes and women who grew up with their fathers. In general, women who grew up without fathers married early compared to women who grew up with their fathers. About $41.8 \%$ of women from father-absent homes married between the ages of 18 and 20 years, whereas only $25 \%$ of women who grew up with their fathers married between the ages of 18 and 20 years. This difference was significant at $X^{2}(3, n=392)=$ 28.081, $p<0.01$. This is also shown in Figure 1. 


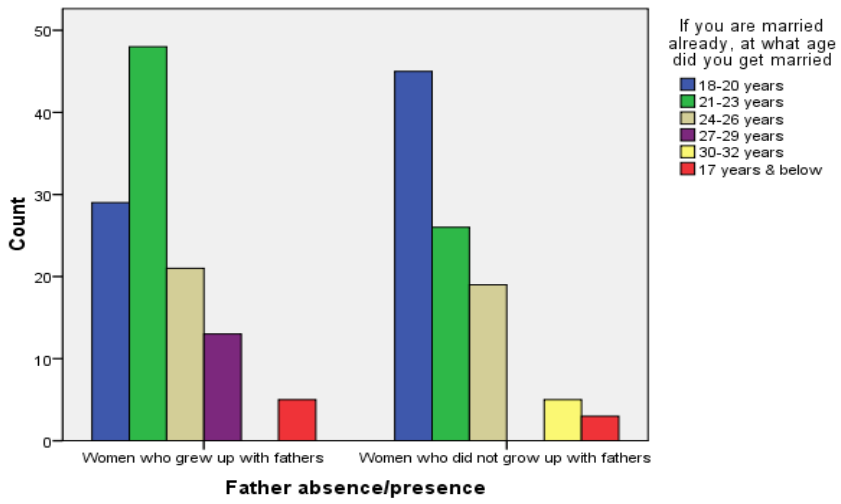

Figure 1. Bar chart showing a comparison of the actual age of marriage between women who grew up with fathers and those who did not grow up with fathers

The preference for the age of marriage was also analysed within the groups of women who grew up without fathers. A significant number of married women who grew up without fathers due to divorce married early. About $54.5 \%$ of women who had divorced fathers married before the age of 20 . This is in contrast to an average of $30 \%$ amongst other groups of father-absent women, such as father died, father migrated and father abandoned who married before the age of 20.

Early marriage can be explained by early maturation that women from father-absent homes may experience due to early stress. Belsky, Steinberg and Draper (1991) argued that if girls experience the high levels of stress during their critical formative years $(<5-7$ years of age), they will accelerate their maturation process. The Psychosocial Acceleration Theory posits that the accelerated maturation process will biologically manifest as earlier menarche and general acceleration of all secondary sexual characteristics. The theory further explains that this early maturation will present psychosocially by the way of early ages at first sexual intercourse, age at first marriage (depending on the cultural manifestation of marriage) and age at first birth (Belsky, Steinberg, Houts \& Halpern-Felsher, 2010).

Early marriages amongst women from father-absent households are explained by a number of scholars as being linked to early menarche which is triggered by childhood stress, particularly father absence. A number of studies found a direct relationship between stressful life events, specifically father departure, and the early onset of puberty. Earlier menarche can lead, in turn, to earlier sexual debut, early marriage and or riskier sexual behavior (Gregorian, 2013; Horne, 2015; Tither \& Ellis, 2008). Socio-economic strains may force young girls from father abandoned homes to get married early so as to support their siblings. Survival analyses showed that women who grew up in father divorced homes or father abandoned homes consistently married at an early age and gave their first birth at an early age as well (Shenk, Starkweather, Kress \& Alam, 2013).

This study revealed that early marriages were more pronounced amongst women who did not grow up with their fathers due to divorce. About $54 \%$ of women who had divorced fathers from this study married before the age of 20. This is below the Zimbabwean singulate mean age at marriage, which is at 21 (United Nations, World Fertility Report, 2009). This trend could be explained by the legacy of divorce that the children may have inherited from their parents. Parental divorce affects detrimentally on the capacity of the children to love and be loved within a lasting, committed relationship (Wallerstein \& Lewis, 2004). The studies on the long-term effects of divorce on adult children show that there is a lower sense of well-being and overall quality of life as well as relationship problems for those who experience the divorce of their parents as children (Christensen \& Brooks, 2001). A number of researchers in the area of marriage and family counselling have concluded that adults raised in divorced families suffer from a deficit in social skills and had special problems in handling conflicts within their own marriage (Amato, 2000). 
This study found that there was no significant difference in the preferred age difference with potential marriage partners for the two groups of women with about $97 \%$ of both groups of women preferring the potential partner to be older than them. However, slight differences were noted on the preferred actual age difference. About $15.4 \%$ of women from father-absent homes preferred the potential spouse to be 10 years older, whereas $8 \%$ of women who grew up with fathers preferred the potential spouse to be 10 years older. On the other hand, $47.1 \%$ of women from father-present homes preferred an age difference with potential sexual mates of less than 4 years, whereas $29.4 \%$ of women from father-absent homes preferred potential sexual mates to have an age difference of 4 years or below. In general, therefore, women from father-absent homes preferred a much wider age difference with a potential mate when compared to women who grew up with their fathers.

\subsection{Preference concerning romantic partner psychosocial character}

This study revealed that father absence or presence during the first 18 years of life moderates a woman's preference concerning romantic partner psychological and social characteristics.

Women who emerged from father-absent homes were of the view that chastity was irrelevant in their selection of a romantic partner. There was a significant difference between the two groups of women on their preference for a romantic partner with no previous experience in sexual intercourse. About $41 \%$ of women who grew up without fathers compared to $26.5 \%$ of women who grew up with fathers indicated that it is irrelevant or unimportant for a preferred romantic partner to have had no previous experience in sexual intercourse. Therefore, women who emerge from father-absent backgrounds are more likely to consider sex as casual. This finding is also consistent with Horne's (2015) findings that adolescents with an absent father preferred to exert a less commitment on a romantic partner and desired to take part in unsafe activities such as unprotected sex, which sometimes leads to pregnancy in their ideal relationship.

The study found no significant differences in the preference of the two groups of women with regard to the following aspects:

i. Sociability of the romantic partner

ii. Dependability

iii. Good housekeeping

iv. Mutual attraction

Women who grew up in fatherless homes did not consider being ambitious and industrious and have a good financial prospect as important aspects in a romantic partner. On the contrary, these were highly rated by women who grew up with their fathers.

\subsection{Preference concerning romantic partner's physical characteristics}

Women who did not grow up with their fathers were of the view that the preferred romantic partner should have good looks. About $69 \%$ of women from father-absent homes compared to $58 \%$ of women from father-present homes were of the view that the preferred romantic partner should have good looks. A within group analysis of the same trend showed that $82.9 \%$ of father migrated women compared to an average of $42 \%$ amongst other groups of father-absent women preferred good looking romantic partners.

Closely related to good looks, the study found that father absence had an effect on the preference of women for masculine romantic partner. More women from father-absent homes than those from father-present homes felt that it was important for a romantic partner to be masculine. There was a significant difference between the two groups of women on their preference for a masculine romantic partner. About $58.3 \%$ of women who grew up without fathers compared to $48.4 \%$ of women who grew up with fathers indicated that it is important for a romantic partner to be masculine. This significance was tested using the Chi-square test of independence, $X^{2}(3, n=392)=13.150, p<0.01$. 
Father absence has been shown to influence preference for physical looks regarding potential and actual sexual partners. Similarly, more women from father-absent homes than those from fatherpresent homes preferred romantic partners with good looks; women from father-absent homes indicated a preference for masculine men as romantic partners. This finding confirms the father absence theory, which states that father-absent females or those that experienced poor family relationships during childhood prefer more masculine men with attractive faces than father present females or those who experienced warm relationships with their parents (Boothroyd \& Perrett, 2008). The possible explanation for this preference on masculine men is that people and, in particular, women who emerged from father-absent homes have a preference for short-term sexual strategy with less committed romantic relationships and sexual behaviour outside committed relationships. Furthermore, the upbringing of some father-absent women, particularly those emerging from father abandoned families, would have socialised them to believe that romantic partners are not to be trusted, and the relationships do not last and as such it will be more worthwhile to focus on shortterm strategies such as finding a masculine man.

\subsection{Most desired characteristic in a potential mate or marriage partner}

Respondents were asked to rate their most desired characteristic in a potential mate or marriage partner from a list of 13 characteristics. There were striking differences in what women from fatherabsent homes desired when compared to women from father-present households.

The most desired characteristic by women who did not grow up with their fathers was 'fatherly figure'. Out of the 13 characteristics, 33.9\% of women who grew up without their fathers compared to only $5.8 \%$ of women from father present homes desired a marriage partner who is a fatherly figure. Five of the desired characteristics are shown in the cross-tabulation (Table 2 ).

Table 2. Cross-tabulation of father absence/presence and most desired characteristic in a marriage partner

\begin{tabular}{|c|c|c|c|c|c|}
\hline & \multicolumn{4}{|c|}{ Most desired characteristic in a potential mate or marriage partner } & \multirow[b]{2}{*}{$\begin{array}{c}\text { Masculi } \\
\text { ne }\end{array}$} \\
\hline & $\begin{array}{c}\text { Kind and } \\
\text { understanding }\end{array}$ & Fatherly figure & Religious & Wants children & \\
\hline $\begin{array}{l}\text { Women who grew } \\
\text { up with fathers }\end{array}$ & $35 \%$ & $5.8 \%$ & $16.5 \%$ & $2.7 \%$ & $0.4 \%$ \\
\hline $\begin{array}{l}\text { Women who did not } \\
\text { grow up with fathers }\end{array}$ & $22 \%$ & $33.9 \%$ & $4.2 \%$ & $6.5 \%$ & $3.6 \%$ \\
\hline
\end{tabular}

Despite the differences in preference between the two groups of women, the desire to have a potential mate or marriage partner who is 'kind and understanding' as well as 'healthy' was common amongst all the respondents. Women who emerged from father-absent homes exhibited a significantly strong desire for a marriage partner who is a fatherly figure. Figure 2 shows all the 13 characteristics in a potential marriage partner and how the two groups of women rated them.

The preference for a fatherly figure as a potential mate could be a way of compensating for lost years of not having a father in one's life. The finding is consistent with the study of Mancini (2010), who revealed that girls from father-absent homes exhibit a desperate need for males to cover up for the emotional loss caused by father absence, which then makes them susceptible to exploitation by adult men. Zirima and Gadzikwa (2017) also found out that female university students looked up to their boyfriends to fill the void left by their absent fathers. 


\section{Bar Chart}

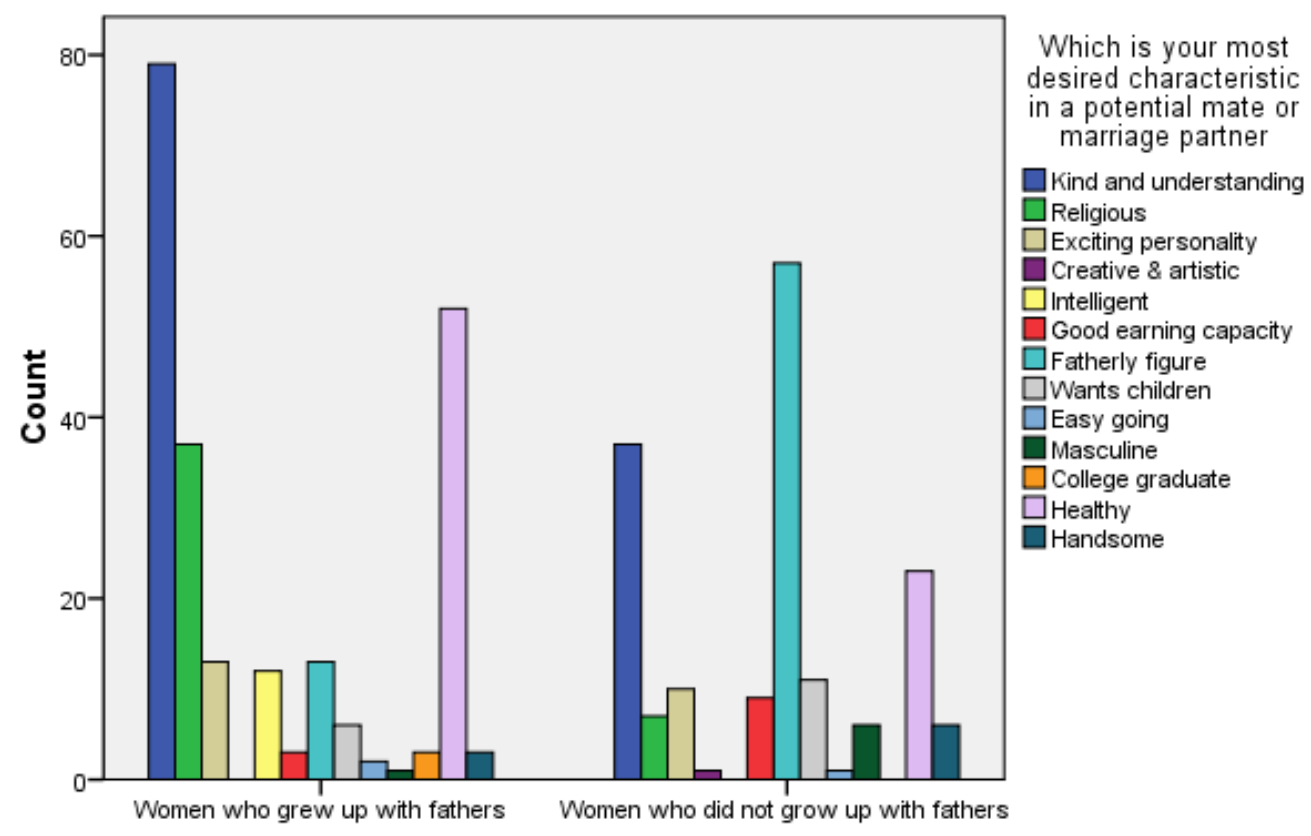

Father absence/presence

Figure 2. Bar chart showing 13 characteristics in a potential marriage partner and how respondents ranked them

\section{Conclusion}

Father absence is a growing trend globally, and its impact can be felt during childhood and also in the adult-life of the children concerned. This study demonstrated the impact of father absence on the sexual partner preference of women. Striking differences were observed on the preferred characteristics on a romantic partner between women who emerged from father-absent homes compared to women who grew up with their fathers. Overall, father-absent women married significantly early when compared to women who grew up with women from father-absent homes getting married at an average of 19 years, whereas women who grew up with their fathers getting married at an average 22 years.

Father absence has an influence in determining the most preferred characteristic in a romantic partner. Women who grew up in father-absent homes showed a preference for a romantic partner who is fatherly figure; this was in sharp contrast to other characteristics which were valued by women who grew up with their fathers such as that the partner should be kind and understanding, healthy and religious. Even though all women generally preferred a romantic partner to be older than them, women who did not grow up with their fathers preferred a larger age difference between them and their partner. Chastity was considered as something not relevant in selecting a romantic partner by women who grew up without fathers.

The study revealed that father absence has an impact on women's preference for physical characteristics in a romantic partner. Women who emerged from father-absent homes showed a preference for romantic partners who have good looks and who are masculine something that was considered unimportant by women who grew up with their fathers. 
Zirima, H. (2020). Father absence and sexual partner preference amongst women in Masvingo urban, Zimbabwe. Global Journal of Psychology Research: New Trends and Issues. 10(1), 01-10. DOI: 10.18844/gjpr.v\%vi\%i.4116

\section{Recommendations}

The findings of this study may pave the way towards a better understanding of the effects of parental relationships on the adult life of children. In light of that fact, the following recommendations are made:

i. A psychosocial intervention model should be developed to help women who grew up without fathers to develop social skills that they may have missed as a result of having grown up without fathers.

ii. An institution which advocates for fathering should be set up to assist children who grow up without fathers. That same institution should help in disseminating information on the repercussions of father absence so as to help people who may be intimately involved with women who emerged from father-absent homes.

\section{Future research}

Future research should explore the impact of father absence amongst married women so as to ascertain if father absence affects relationships within a marriage.

\section{References}

Amato, P. R. (2000). The consequences of divorce for adults and children. Journal of Marriage and Family, 62(4), 1269-1287.

Aye, E. N., Akaneme, I. N., Adimora, E. D., Offorka, T. O., Robinson, A., Nwosu, P. O. \& Ngozi, F. (2016). Family conflict and managing strategies: implication for understanding emotion and power struggles. Global Journal of Psychology Research: New Trends and Issues, 6(3), 148-159. doi:10.18844/gjpr.v6i3.1454

Baglama, B. (2017). Depression as an outcome or cause of sexual dysfunctions: a review study. Global Journal of Psychology Research: New Trends and Issues, 7(3), 117-124. doi:10.18844/gjpr.v7i3.2857

Belsky, J., Steinberg, L. \& Draper, P. (1991).Childhood experience, interpersonal development, and reproductive strategy: an evolutionary theory of socialization. Child Development, 62, 647-670.

Belsky, J., Steinberg, L., Houts, R. M. \& Halpern-Felsher, B. L. (2010).The development of reproductive strategy in females: early maternal harshness $\rightarrow$ earlier menarche $\rightarrow$ increased sexual risk taking. Developmental Psychology, 46, 120-128.

Boothroyd, L.G. \& Perrett, K. (2008). Father absence, parent-daughter relationships and partner preferences. Journal of Evolutionary Psychology, 6(3), 187-205.

Centre for Disease Control and Prevention (CDC). (2015). National marriage and divorce rate trends. New York, NY: National Vital Statistics System.

Christensen, T.M. \& Brooks, M.C. (2001). Adult children of divorce and intimate relationships: are view of the literature. Family Journal, 9, 289-294.

Cohen, L., Manion, L. \& Morison, K. (2000). Research methods in education. London, UK: Routledge Falmer.

Gregorian, A.(2013). Gender selection and abortion in Armenia. Washington, DC: IREX.

Horne, Z. (2015). Belief updating in moral dilemmas. Review of Philosophy and Psychology, 4(4), 705-714.

Hosegood, V.\& Madhavan S. (2010). Data availability on men's involvement in families in sub-Saharan Africa to inform family-centred programmes for children affected by HIV and AIDS. Journal of the International AIDS Society, 13(2), 55-67.

Madhavan, S., Townsend, N.W. \& Garey, A. I. (2012). 'Absent breadwinners': father-child connections and paternal support in rural South Africa. Journal of South African Studies, 34(3), 647-663.

Makofane, M. (2015). 'Not all men are fathers': experiences of African women from families with absent fathers. Social Work, 51(1), 67-74.

Mancini, L. (2010). Father absence and its effects on daughters (Unpublished master's thesis). University of Canterbury, Christchurch, New Zealand. 
Meintjies, H. \& Hall, K. (2010).Demography of South Africa's children. Cape Town, South Africa: South African ChildGauge 2010/2011.

Mikaeli Manee, F. \& Aria, A. M. (2018). Personal and social predictors of risky sexual behaviours in Iranian youth. Global Journal of Psychology Research: New Trends and Issues, 8(1), 10-24. doi:10.18844/gjpr.v8i1.3269

Mokomane, Z. (2012). Social protection as a mechanism for family protection in Sub-Saharan Africa. International Journal of Social Welfare, 22(3), 248-259.

Nyanjaya, A.K. \& Masango, M.K. (2012). The plight of adolescent male children with absent fathers in Zimbabwe. Theological Studies, 68(1), 17-27.

Punch, K.F. (2004). Introduction to social research; quantitative and qualitative approaches. London, UK: Sage Publications.

Ratele, K., Shefer, T. \& Clowes, L. (2012). Talking South African fathers: a critical examination of men's constructions and experiences of fatherhood and fatherlessness. South African Journal of Psychology, 42(4), 553-563.

Shenk, M.,Starkweather, K., Kress, H.C. \& Alam, N. (2013). Does absence matter? A comparison of three types of father absence in rural Bangladesh. Human Nature, 24(1), 76-110.

Thomassin, K. \& Suveg, C. (2014). Reciprocal positive affect and well regulated adjusted children. A unique contribution of fathers. Parenting, 14(1), 28-46.

Tither, J.M. \& Ellis, B.J. (2008). Impact of fathers on daughters' age at menarche: agenetically- and environmentally-controlled sibling study. Developmental Psychology, 44, 1409-1420.

United Nations, World Fertility Report. (2009). Department of economic and social affairs, population division. New York, NY: United Nations Publication.

Wallerstein, J. S., Lewis, J. M. (2004). The unexpected legacy of divorce: report of a 25-year study. Psychoanalytic Psychology, 21, 353-370.

Zirima, H. \& Gadzikwa, P. (2017). Experiences of female university students who grew up in father absent homes. International Journal of Education and Psychology in the Community, 7(1), 16-30. 